\title{
Ética econômiea e solidariedade na Obra Lucana
}

\section{Economic ethics and solidarity in Lukan Work}

\author{
Agnese Costalunga* \\ Tarlei Navarro Pádua Souza**
}

Recebido: 30/05/2019. Aceito: 16/08/2019.

Resumo: Este artigo tem por objetivo aprofundar o tema "os pobres e o apelo de solidariedade aos ricos em Lucas", destacando que o autor da Obra Lucana tinha uma visão ampla do contexto socioeconômico e político de seu tempo e não deixou passar despercebidos os problemas sociais latentes, que clamam por justiça social. Nessa perspectiva, desejamos seguir uma ética proposta e manifestada por Lucas, onde as riquezas têm um papel social e devem ser direcionadas à partilha. Para tanto, este estudo apresenta que a chave da questão na comunidade lucana foi despertar a proposta de Jesus ao devolver a esperança messiânica aos pobres, com insistente apelo aos ricos à solidariedade, o caminho ético do amor.

Palavras-chave: Pobres. Ricos. Solidariedade. Evangelho segundo Lucas.

Abstract: This article's aim is to deepen the motif of the "the call to solidarity from the wealthy towards the poor" in lukan work, pointing out the broad view about the social, economic and political context that the author of lukan work had of his time. He really addressed this issue which strongly emerged as a call for social justice. From this perspective we want to take the direction given by Luke, who expressed so clearly that the social role of wealth and possessions is sharing. From this point of view this study will present the clue from which the lukan communities proposed a new model of solidarity, based in the Kingdom of God's values proposed by Jesus in order to give back hope to the poor and conversion for the wealth through the way of solidarity.

Keywords: Poor. Rich. Solidarity. Gospel according to Luke.

* Doutora em Teologia da Missão (Faculdade de Teologia Nossa Senhora da Assunção, São Paulo, 2007). Mestra em Teologia (Pontifícia Universidade Católica, São Paulo, 2013). Docente em Teologia da Missão no ITESP e Introdução ao Pensamento Teológico na PUC-SP. E-mail: costagnes@uol.com.br

** Mestrando em Teologia (Pontifícia Universidade Católica de São Paulo). Graduado em Curso Superior de Filosofia (Instituto de Filosofia São Boaventura, IFSB, São Paulo, 2000). Graduado em Teologia (Pontifícia Universidade Católica, Campinas, 2004). Graduação em Teologia (Faculdade Vicentina, FAVI, Curitiba, 2017).

E-mail: pe.tarleinavarro@gmail.com 


\section{Introdução}

Para Lucas, o tema "os pobres" é abrangente, já que engloba nessa temática todos os injustiçados de seu tempo, o que torna a sua obra um tratado sobre o assunto. As suas comunidades estavam espalhadas em diversas regiões do império romano e inseridas em um modelo socioeconômico que impunha a todas as colônias altos tributos, taxas, arrendamento e mesmo confisco das terras ${ }^{1}$. Portanto, pode-se imaginar que Lucas tem uma visão abrangente do seu tempo e, por isso, mostra-nos grande preocupação social, firmando que sua preferência está sempre do lado dos pobres, principalmente dos marginalizados, dos pecadores públicos e das mulheres.

É válido supor que o evangelho de Lucas pode ser chamado de Evangelho dos pobres e dos marginalizados, pois mostra Jesus muito próximo das pessoas simples e marginalizadas de sua época, o que será constatado em toda a obra lucana ${ }^{2}$. Nossa intenção é adentrar o contexto social do Império Romano, no qual as comunidades lucanas estão inseridas, em contexto de profundas desigualdades sociais, e tirar dessa história uma mensagem. Sendo assim, cabe-nos adentrar o mundo de Lucas tentando explicar a situação de suas comunidades, historicamente, e, teologicamente, legitimá-la. Esse objetivo foi, certamente, o desafio do autor dessa obra.

Percebe-se, pela leitura do texto, que o trabalho redacional de Lucas é mais atento que os outros sinóticos referentes às situações socioeconômicas (cf. Lc 6,20.24;12,16-21;16,1-8; 16,19-31;19,1-10), e que coloca de modo explícito que "felizes os pobres" em contrapartida a "ai dos ricos". Daqui já se tira uma mensagem de que as riquezas são grande obstáculo para acolher a Palavra e seguir Jesus (cf. Lc 8,14, 1624-5, 18, 18-27). Nessa direção, é válido supor que, embora a conversão de Zaqueu tenha uma repercussão econômica muito exigente, isso não implica o total abandono dos bens materiais. Por outro lado, também é possível observar que Lucas geralmente sublinha tanto o perigo que

1 GONZALES, Justo. Faith and Wealth: A History of Early Christian Ideas on the Origin, Significance, and Use of Money. Harper \& Row, San Francisco, 1990. p. 42.

2 MAZZAROLO, I.; KONINGS, J. Lucas o evangelho da graça e da misericórdia. S. Paulo: Loyola, 2016. p. 9-10.

3 SEGUNDO, J. L. A história perdida e recuperada de Jesus de Nazaré. Dos sinóticos a Paulo. São Paulo: Paulus, 1997. p. 152. 
supõe as riquezas, como também o radicalismo que exige no seguimento de Jesus ${ }^{4}$.

Verificar-se-á uma teologia que está viva por trás do tema "pobres e ricos em Lucas" que precisa ser analisada, já que o autor reproduz atitude e pensamento originais de Jesus, reflexos vivos do ambiente do evangelista e de suas comunidades cristãs ${ }^{5}$. Outro fato que se destaca é a idealização do cristianismo primitivo como movimento revolucionário em favor dos pobres e deserdados que encontravam, em parte, a sua justificação na Obra Lucana.

Percebe-se que aqui não apresentamos uma resposta mágica que solucione a situação social, mas buscamos, através deste estudo, despertar caminhos e protagonismos em defesa dos menos favorecidos. Apoiamo-nos no ideal de que a tarefa do homem no seguimento de Jesus é anunciar o Reino de Deus, firmado na morte e ressurreição de Jesus, com um estilo de vida em que as relações humanas, e também socioeconômicas, exprimam fraternidade.

Ter-se-ia de dizer que no projeto evangélico de Lucas os bens se tornam sinal e instrumento para realizar a comunidade solidária que anuncie e antecipe o Reino de Deus, que é meta última da história. Verificou-se com esta pesquisa que desde a criação do mundo, o universo foi criado como um habitar para todos os filhos de Deus. Essa vontade amorosa foi prejudicada pelo pecado e Lucas conhece um remédio: o Reino. Exemplo disso é o chamado insistente em abandonar-se na providência divina, tendo-se como princípio fundamental do Reino, a solidariedade com os irmãos (cf. 12, 22-31). É somente assim que podem conviver o lobo e o cordeiro, a vaca e o urso pastarão junto com a criança e o urso com a vaca (Is $11,1-11)^{6}$.

\section{Contexto histórico de Israel no primeiro século}

Destaca-se que todos os eventos narrados por Lucas pertencem à história de Israel e, consequentemente, não podem ser atribuídos parcialmente a épocas históricas particulares e separadas do tempo de

4 AGUIRRE, RAFAEL; BERNABÉ, Carmen; GIL, Carlos. Guías de lectura de lós evangelios de Mateo, Marcos e Lucas. Estella (Navarra): Verbo Divino, 2014. p. 219.

5 FABRIS, R.; MAGGIONI, B. Os Evangelhos II. São Paulo: Loyola, 2010. p. 108.

6 DILLMANN, R.; PAZ, C. A. M. Comentario al Evangelio de Lucas: Um comentário para la actividad pastoral. Estella (Navarra): Verbo Divino, 2006. p. 391. 
Israel $^{7}$. Nessa direção, Teissen e Merz confirmam que o judaísmo no tempo de Jesus tinha algumas convicções básicas, como o monoteísmo e a aliança de Deus com Israel: templo e sinagogas, sacrifícios e liturgia da palavra, assim como os escritos sagrados e tradições (orais e escritas). Jesus compartilhava destas convicções básicas e formas de expressão do judaísmo, isto é, do que é chamado "comum judaism" ${ }^{8}$.

Sendo assim, verifica-se que "escrevendo na época da ruptura entre judeus e cristãos, confirmada na reunião de Jâmnia, por volta de $85 d$. C., Lucas abandona o judaísmo para dedicar sua obra, com particular atenção, ao leitor pagão, ao estrangeiro e ao greco-romano interessado em saber como arrastar as perseguições dos judeus. Nesta óptica, que inclui todos os filhos de Adão, as figuras do pobre, da mulher e do estrangeiro desempenham um papel fundamental ao longo de toda obra, particularmente na compreensão "política" de Jesus no anúncio do Reino de Deus. Esta opção clara pelos que estão "fora" dos círculos das decisões, pelos que são considerados o "estorvo" e o atraso da sociedade, caracteriza esta obra como o evangelho da misericórdia e da inclusão".

Verifica-se ainda que três argumentos direcionam-se para a concepção de que as comunidades destinatárias da obra lucana seriam originariamente pagãs e de cultura grega. Um motivo é a dedicatória dos dois volumes a um personagem de nome grego: Teófilo. Outra indicação tem por base a clara intencionalidade de Lucas de relacionar sua exposição do fenômeno Cristo e de sua continuação na Igreja com as tradições literárias do mundo greco-romano. E, por fim, o interesse de Lucas em apresentar a abertura da salvação prometida a Israel no Antigo Testamento aos pagãos ${ }^{10}$. Jesus é salvador de todos os homens, sendo assim, também a Igreja abraça a quantos acolhem a mensagem salvífica.

Constata-se também que a terra dos judeus era chamada pelos romanos de Palestina e estava dentro do Império Romano, território grandioso que foi conquistado pelos povos que vinham de Roma e que se estendeu desde a Inglaterra até as margens do Saara, desde o estreito

7 SCHNELLE, U. Teologia do Novo Testamento. Santo André: Academia Cristã; São Paulo: Paulus, 2010. p. 608.

8 TEISSEN, G.; MERZ, A., O Jesus histórico: um manual. S. Paulo: Loyola, 2004. p. 148.

9 MAZZAROLO, I.; KONINGS, J. Lucas o evangelho da graça e da misericórdia. S. Paulo: Loyola, 2016. p. 10.

10 FITZMYER, J. A. El Evangelio según Lucas: Introducción General. vol. I, Madrid: Cristiandad, 1986. p. 108. 
de Gibraltar até Constantinopla e o rio Eufrates. Os romanos invadiram a Palestina no ano 63 a. C. e fizeram deste país uma colônia. Com artimanha e força, Roma dominava e os dominadores se apresentam como representantes de uma nação amiga que vinha para ajudar. Traziam seus governadores, seu exército, cobravam impostos, construíam cidades, estradas e portos que permitiam a comunicação com a capital e a circulação e dinamização do comércio. Usavam de uma artimanha que era fingir que aceitavam a autonomia religiosa e política do povo: podiam ter sua religião, desde que reconhecida como lícita, e até possuir um Rei, como no caso de Herodes na Palestina. Essa era uma estratégia de dominar sem que o povo percebesse que estava sendo dominado. No entanto, o dominador estava vigilante e qualquer ameaça de independência e revolução era reprimida violentamente pelo poderoso exército. Os governadores locais exerciam, de fato, essa função de guardiões da ordem. Não zelar pela ordem era traição ao imperador e fim de carreira política ${ }^{11}$.

Conclui-se que os países unificados nesta imensa região denominada de Império Romano curvavam-se diante de Roma e ainda estavam orgulhosos de pertencer a esse império. Observa-se, ainda, que esse era o período da chamada "Pax Romana", durante o qual o comando do poder era dado por Roma, portanto uma paz determinada "de cima", estabelecida pelo centro do poder. Para se perceber toda a realidade deste período, é necessário um olhar "a partir de baixo", para não ser esquecida toda a realidade de sofrimento, opressão, a fim de que os vencedores da história não triunfem novamente sobre as vítimas da mesma história.

Neste sentido, acredita-se que seja necessário uma pequena análise de algumas situações nesse tempo, seja militar, política, econômica, jurídica, cultural ou religiosa.

\subsection{Contexto Social, Político e Econômico do Primeiro Século na Palestina}

No contexto militar, o imperador era o chefe do exército e havia um interesse comunicativo de associar a paz ligada ao aspecto militar. A paz estabelecida era mantida por meios militares e acompanhada de rios de sangue e lágrimas, devastações com fogo e com espada. Diante disto, restava aos povos submetidos se renderem a esse poder opressor e

11 VV. AA. Introdução ao Segundo Testamento - Eu vim para que todos tenham vida em plenitude. S. Paulo: Paulus, 2014. p. 11. 
aceitá-lo mesmo com terror e medo, com prontidão para executar ordens. Com o poder nas mãos, Roma destruía e arrasava muitas vezes as cidades conquistadas, porque "a fama da guerra documenta-se em ruínas" (Klaus Wengst, "Pax"). O historiador Tácito (em seu livro Anais) apresenta como o seu chefe do exército romano exterminava a ferro e fogo todos aqueles em quem reconhecia atitude hostil aos romanos. Foi realmente grande o preço que os povos conquistados por Roma pagaram para usufruir dos "benefícios" que ela lhes oferecia ${ }^{12}$.

No sistema romano, tudo era executado debaixo de ordem. O imperador presidia o Império e tudo estava estruturado em direção a ele e dele emanava todo o poder de comando, pois se tornou a mais alta representação do Império. Os deuses eram os protetores e salvadores do Império, por intermédio do Imperador, que respondia por todos os bens do Império. Era senhor da vida e da morte para os povos. Ele não devia receber em vida veneração divina e ações cultuais, entretanto a pessoa de Augusto recebeu em Roma honras divinas, por intermédio de poetas como Virgílio e Horácio. Quando Plínio, como governador, observou o processo de cristãos, examinou a lealdade política para com o Império Romano, que era a única coisa que lhe interessava, exigindo a execução de rituais religiosos para com o imperador e os deuses romanos. Aquele que se confessava cristão era considerado culpado de deslealdade e, portanto, de um delito político, assim ele mandava executá-10 ${ }^{13}$.

No contexto político, vale lembrar que o poder romano propagava que oferecia segurança. A primeira face dessa segurança era a proteção contra toda ameaça de fora das fronteiras do Império Romano. Tal segurança incluía também a exclusão de desavenças e conflitos entre as diversas regiões do Império, bem como a ausência de medo nos campos, nas casas e nas viagens. Para os políticos, a tarefa primordial era a de ocupar-se com a harmonia. Nesse sentido, os povos subjugados viviam uma miserável existência de escravos (Tácito, Anais). Não era, de forma alguma, tempo de liberdade. O sistema de escravatura revelava que a liberdade era apenas um slogan (Klaus Wengst, A Paz Romana), pois até em Roma a liberdade era limitada. Josefo (Guerra Judaica) conta que, pouco antes da irrupção da guerra judaica, quando tudo já a prenunciava, os sumos sacerdotes que exerciam influência e o Sinédrio foram ter

12 VV. AA. Introdução ao Segundo Testamento - Eu vim para que todos tenham vida em plenitude. S. Paulo: Paulus, 2014. p. 18-19.

13 GNILKA, J. Jesus de Nazaré: mensagem e história. Petrópolis: Vozes, 2000. p. 67. 
conversações com o Rei Antipas II e há indícios de que esses homens eram daqueles que "procuravam a paz por causa de sua fortuna" 14 .

Desse modo, é também válido lembrar de Pôncio Pilatos, governador da Judeia, que a governou durante a vida pública de Jesus. Segundo os relatos de Lohse, Pilatos foi procurador (26-36 d.C.). Lembrando Filo de Alexandria, relata-se que sua administração consistia em "corrupção, violência, roubos, tortura, ofensas, contínuas execuções sem processo, crueldade habitual e insuportável" (legatio ad Gaium 302). Nunca se levaram em consideração os sentimentos religiosos dos judeus. Importante frisar que Pilatos era um homem duro e sem escrúpulos, certamente não tinha receio de, após um interrogatório sumário, sentenciar à morte na cruz um judeu, entregue pelo Sinédrio como pessoa politicamente suspeita. Assim, Jesus de Nazaré morreu fora de Jerusalém, submetido pelo procurador romano ao castigo mais vergonhoso que o mundo antigo conhecia ${ }^{15}$. Portanto, corrupção, violência, roubos, comprovam que Pilatos era um homem desonesto e sem escrúpulos e isso já é suficiente para perceber que o Oriente Médio estava corrompido pelo dinheiro, o que justifica os insistentes discursos de Jesus com relação ao perigo das riquezas, tão presentes na Obra Lucana.

Outro fato a ser destacado é que, para o Império Romano, a situação econômica era importantíssima, pois a riqueza econômica de um país conquistado e sua capacidade de produção deviam ser orientadas para as necessidades de Roma. Os tesouros do solo não pertenciam àquele que 0 habitava e o cultivava, mas ao superior, ao vencedor, e vale destacar que, sobretudo o ouro, exercia atração muito grande. Os espólios das guerras superavam toda a imaginação e estavam colecionados no templo da Paz. Os impostos eram imensos, bem como as alfândegas, as contribuições, os tributos e recrutamentos. A exploração das províncias e o espólio de guerra favorecia de maneira especial a cidade de Roma, ou seja, em primeiro lugar, a camada superior ${ }^{16}$. Segundo Gnilka, "o grande número de impostos era sentido como uma carga que oprimia a população de uma maneira toda particular". ${ }^{17}$

14 VV. AA. Introdução ao Segundo Testamento - Eu vim para que todos tenham vida em plenitude. S. Paulo: Paulus, 2014. p. 18-19.

15 LOHSE, E. Contexto e Ambiente do Novo Testamento. S. Paulo: Paulinas, 2000 p. 18-19.

16 VV. AA. Introdução ao Segundo Testamento - Eu vim para que todos tenham vida em plenitude. S. Paulo: Paulus, 2014. p. 17.

17 GNILKA, J. Jesus de Nazaré: mensagem e história. Petrópolis: Vozes, 2000. p. 67. 
Os contrastes nas condições sociais também eram grandes e se constatavam por uma distribuição extremamente desigual da terra que, em sua maior parte, por concentração de posse, se encontrava nas mãos de poucos.

As diferenças alarmantes tornaram-se marcas desse tempo, o que caracterizou um período difícil em que o mundo político e econômico estava debaixo das exigências pesadas dos impostos a pagar e do terror, o que ocasionava nos soldados romanos o medo de rebeliões populares que se alastravam de tempos em tempos. E, consequentemente, debaixo de ordens revidavam com violenta repressão ${ }^{18}$.

Dessa forma, torna-se evidente que as camadas sociais da população apresentavam sérias diferenças. Bem no alto, encontrava-se uma inchada faixa de latifundiários, que se podia dar ao luxo de morar numa casa em Jerusalém. Embaixo, ficava a massa dos pobres agricultores e diaristas, e eram estes os que se achavam em pior condição de vida. Viviam da mão para a boca, geralmente não encontravam trabalho a não ser por um tempo limitado. Mas existia também uma camada social média e a ela pertenciam os artesãos, os pequenos comerciantes, mas também os sacerdotes (levitas) comuns. A maioria não podia se dar ao luxo de morar na capital. Jericó era considerada uma cidade dos sacerdotes ${ }^{19}$.

Observa-se que, mesmo na questão jurídica, havia diferenças alarmantes, pois o poder e o dinheiro reinavam a favor de quem sabia gritar mais alto e forte. O Império Romano era destemido e sem escrúpulos, não tinha temor em defender-se e oprimir com veemência a grande camada de pobres que havia na época. Nesse sentido, confirma-se que "havia realmente certa segurança jurídica no Império Romano, mas a justiça de classe mostrou-se, por um lado, no tratamento benigno dos membros, de culpa comprovada, da classe superior e, por outro lado, na desvantagem dos pequenos" ${ }^{\prime 20}$.

A vida em cidades era ponto necessário da cultura e civilização romana. A urbanização da população nas províncias "bárbaras" serviu de meio, utilizado conscientemente, para romanizar essas regiões. $\mathrm{O}$ Império subsidiava-se com recursos públicos, para construir templos,

18 LIBÂNIO, J. B. Linguagens sobre Jesus 3: de Cristo carpinteiro a Cristo cósmico. São Paulo: Paulus, 2013. p. 77.

19 GNILKA, J. Jesus de Nazaré: mensagem e história. Petrópolis: Vozes, 2000. p. 63-64.

20 VV. AA. Introdução ao Segundo Testamento - Eu vim para que todos tenham vida em plenitude. S. Paulo: Paulus, 2014. p. 17. 
praças públicas e casas na cidade. Educavam-se os filhos dos nobres nas artes liberais. O domínio romano cuidava de dotar as cidades de instalações públicas, seja na construção de banhos e adutoras de águas, de teatros e ginásios de esportes, de pórticos, templos ${ }^{21} \mathrm{e}$ oficinas e escolas. Os jogos, sobretudo as lutas de atletas e de gladiadores, eram aspecto importante da vida nas cidades das províncias. Este luxo chocava-se com a triste realidade da população simples e pobre, que vivia na miséria e na fome.

\section{Realidade das Comunidades Lucanas}

Vale lembrar que a comunidade lucana vivia aparentemente uma profunda crise de identidade e de continuidade. Havia necessidade de uma reflexão sobre alguns temas, como a relação com Israel, a problemática da parusia, a posição do novo "caminho" na sociedade greco-romana, as relações com o estado romano e, inclusive, o tema ricos e pobres. ${ }^{22}$ Tais problemáticas deixaram, nas comunidades lucanas, diferenciais importantes.

Recorda-se que toda a ênfase dada por Lucas aos pobres parece caminhar em uma única direção: mostrar a salvação em Jesus, único Salvador, que não oferece salvação pelo poder, força, dinheiro, glória humana, meios que evidentemente não salvam, porém marginalizam os pobres e são causa de sofrimento e que fique claro, como enfatiza o evangelista, que a salvação de Jesus é total, porque salva de tudo, inclusive do pecado e da morte, aonde não chega a salvação humana, e salva a todos, é universal, mas os marginalizados da salvação humana são os privilegiados, especialmente os pobres-miseráveis e os pecadores ${ }^{23}$.

21 Cf. GNILKA, Joachim. Jesus de Nazaré - mensagem e história. Petrópolis, 2000. p. 67. Por exemplo, "a construção do templo de Jerusalém, ordenada por Herodes e que se prolongou durante décadas, ofereceu trabalho e pão a muitas pessoas. Britadores, carpinteiros, artífices, todos estes encontraram trabalho aqui. Na construção deve ter trabalho uns 18.000 trabalhadores, pois se refere que após o encerramento da obra, entre 62 e 64 d. C.. Na época Agripa II, por razões sociais e por insistência do povo, para dar trabalho às pessoas, mandou calcar Jerusalém com pedras brancas. O dinheiro para isto ele tirava do tesouro do templo, de que podia dispor. O tesouro do templo recolhia, com o correr do tempo, somas consideráveis".

22 SCHNELLE, U. Teologia do Novo Testamento. Santo André: Academia Cristã; São Paulo: Paulus, 2010. p. 679.

23 MONASTERIO, R. A.; CARMONA, A. R. Evangelhos Sinóticos e Atos dos Apóstolos. São Paulo: Ave-Maria, 2000. p. 310-342. 
Portanto, é dentro deste contexto, com todas as suas implicações diretas ou indiretas, em uma realidade abrangente e de consequências variadas, que Lucas escreve sua obra. Evidentemente que se entende aqui o porquê ou os porquês de sua predileção pela temática dos empobrecidos do Reino.

\section{Os pobres em Lucas e o clamor pela ética}

Verificou-se que Lucas coloca em seu retrato de Jesus acentos que chamam a atenção. Entre eles está a volta aos pobres, que é refletida na ética, o que nos leva a observar que esta ética está inserida no conceito lucano de origem e continuidade e é de importância central para o pensamento do evangelista, como mostra a pergunta "Que devemos fazer/ Que devo fazer?” (Lc 3,10; 10,25; 16,3; At 2,37; 16,30). ${ }^{24}$. Aqui há realmente uma provocação nas comunidades lucanas, lembrando-as com destaque o retorno de uma nova ética latente no evangelho e nos Atos dos Apóstolos, sendo, portanto, uma característica de Lucas e está enraizada concretamente na atuação de Jesus e deve, assim, estar também firmada na vida da comunidade primitiva.

Isso reforça que a proposta de Jesus sobre o Reino de Deus traz, ao mesmo tempo, uma valorização de grupos estigmatizados dentro de Israel. Grupos com considerável deficiência social, física ou moral ganham uma proximidade especial pelo Reino ${ }^{25}$. Mostra-se o rosto desses grupos com deficiência social, sendo eles os pobres, os famintos, os que choram, os perseguidos, os deficientes físicos e as crianças, pois são bem-aventurados e o Reino de Deus lhes pertence (cf. Lc 6,20ss). No sentido "real" há, na tradição bíblica, mais do que ausência de riqueza: "pobre" é todo aquele cujos direitos são violados. Nesse conceito, está implícito o elemento de falta de poder e, por isso, na primeira bem-aventurança, Jesus declara os pobres felizes, não porque vão se tornar ricos, mas porque participarão do poder de Deus, pois a eles pertence o Reino de Deus. Sua deficiência é verdadeiramente uma falta de poder para impor-se contra a injustiça.

24 SCHNELLE, U. Teologia do Novo Testamento. Santo André: Academia Cristã; São Paulo: Paulus, 2010. p. 654.

25 TEISSEN, G.; MERZ, A., O Jesus histórico: um manual. S. Paulo: Loyola, 2004. p. 294. 
Portanto qualificar o evangelho de Lucas como o evangelho dos pobres não é excesso, mas uma constatação, pois essa é a boa nova de Deus em favor dos que se encontram, de alguma maneira, privados do básico para viverem. A verificação do vocabulário usado atesta preferência e interesse do autor pela categoria dos pobres. Lucas usa o termo

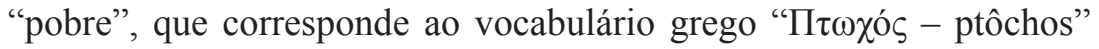
(uma vez penichros), dez vezes num total de vinte e quatro vezes em todo Novo Testamento (cinco vezes em Mt, cinco vezes em Mc). O sentido desse termo é prevalentemente social, ou seja, designa uma pessoa ou categoria de pessoas destituídas de bens, que dependem da esmola privada ou assistência pública.

No Léxico Grego-Português do Novo Testamento - baseado em

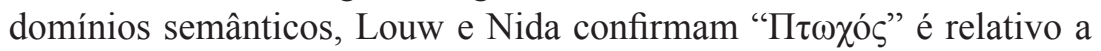
ser pobre e sem recursos, com a implicação de se tratar de uma situação que persiste - "pobre". ${ }^{26}$

"Em todas as sociedades existem pobres, assim que não é dificil encontrar um termo adequado para designar essas pessoas. No entanto, em algumas línguas, são usadas expressões idiomáticas, como, por exemplo, 'aqueles que se vestem com farrapos' ou 'aqueles que têm as costelas sempre à mostra". ${ }^{27}$

Em outra estatística, Morgenthaler confima que, "para indicar

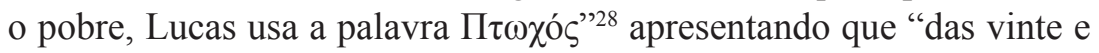
quatro vezes que o termo aparece nos Evangelhos, Lucas é o evangelista que mais o usa (dez vezes) para indicar o pobre, mendicante. Mc (cinco vezes); Mt (cinco vezes); Jo (quatro vezes). Portanto, confirma-se que, em todo o NT, o termo aparece trinta e quatro vezes e, "além de apontar para uma situação econômica muito crítica, realça, a partir da raiz do verbo $\pi \tau \omega ́ \sigma \sigma \omega$, 'acocorar-se de medo; estar espantado; mendigar' 29 , de onde provém a atitude de vergonha e de temor do pobre diante dos ricos e eruditos da sociedade. Sentindo-se inferiorizado, ele se curva perante os poderosos. É a triste situação do oprimido diante dos seus opressores.

26 LOUW, J.; NIDA, E. Léxico grego-português do Novo Testamento - baseado em domínios semânticos. Barueri: Sociedade Bíblica do Brasil, 2014. p. 502.

27 Ibidem.

28 MORGENTHALER, R. Statistik des Neutestamentlichen Wortschatzes. Zürich-Frankfurt am Main: Gotthelf-Verlag, 1958. p. 138.

29 PEREIRA, I. Dicionário Grego-Português Português-Grego. 5. ed. Porto: Apostolado da Imprensa, 1976. p. 504. 
Esse grupo social aparece com frequência na narração de Lucas (cf. Lc $6,20 ; 7,22 ; 14,13.21 ; 16,20.22 ; 18,22 ; 19,8 ; 21,3)^{30}$.

Lucas também usa o termo $\pi \varepsilon v$ ¿xpós "pobre" ${ }^{11}$ para indicar uma situação de extrema miséria, qualificando o estado daquele que é obrigado a trabalhar duramente para obter os recursos necessários ao próprio sustento. É verdade que os termos usados por Lucas e o contexto em que aparecem indicam que não se refere aos pobres em sentido moral e religioso, em primeiro lugar, os anawin do Antigo Testamento que vivem plenamente submissos a Deus.

"Importante aqui que, na pesquisa sobre a etimologia da palavra 'anî, indica que ela vem da raiz nh, a qual tem um campo semântico variado de significações dentro da Bíblia Hebraica (BH). É o que é chamado de "raizes homônimas". São estas: 'nh I ("responder"), 'nh II ("ser afligido"), 'nh III ("mostrar-se, manifestar-se"), 'nh IV ("cantar"). Seguindo a visão deste dicionário, o adjetivo 'an̂̀ vem da raiz verbal `nh II ("ser afligido"). Assim, o 'anî é alguém que está em desespero por causa de alguma aflição a que ele está sujeito naquele momento"32.

Portanto, os pobres formam um conjunto heterogêneo que, segundo Monasterio e Carmona, se pode separar em três grupos sendo o primeiro os pobres-miseráveis, mendigos, o que no hebraico seria o mesmo que "anawin", os pobres miseráveis do Antigo Testamento, que possuem carências de diversos tipos as quais lhes impedem de viverem como pessoas. É um grupo amplo, onde estão incluídos os miseráveis, mendigos, humilhados, famintos, aleijados, coxos, mancos, viúvas necessitadas, mulheres estéreis (cf. Lc 1,48.52.53; 6,21; 14,13.21; 16,20.22; 18,22; $19,8 ; 21,3)$. Todos eles são os destinatários privilegiados do reino de Deus e, por isso, da obra de Jesus (cf. Lc 4,18; 7,22; 14,21; 16-20-25). A razão é teológica e se radica nas promessas de Deus (cf. Lc 4,18; 7,22) e na lei da compensação disposta por ele (cf. Lc 16,20), segundo a qual haverá troca total de sorte dos ricos e pobres na outra vida. Deus não quer esse tipo de carência, muitas vezes criadas pelo egoísmo dos homens e

30 CASALEGNO, A. Lucas: a caminho com Jesus missionário. São Paulo: Edições Loyola, 2010. p. 297.

31 MORGENTHALER, R. Statistik des Neutestamentlichen Wortschatzes. Zürich-Frankfurt am Main: Gotthelf-Verlag, 1958. p. 131.

32 SANTOS, P. E. C., O 'ebyôn ("pobre") e o ‘anî ("pobre") dentro do livro do Deuteronômio. Disponível em: <http://revistas.fflch.usp.br/vertices/article/view/469>. Acesso em: 06 fev. 2019. 
promete a salvação a esses pobres (cf. Lc 1,53). No presente, é necessária à cooperação dos homens, cujas obras em favor dos necessitados serão recompensadas por ele (cf. Lc 14,13) e, no futuro, compensando essa situação ${ }^{33}$. É notório que o segundo grupo de pobres é composto pelos cristãos perseguidos que foram reduzidos à situação de miséria por fidelidade à fé e o terceiro grupo é dos que vivem a pobreza com austeridade, sendo este um valor para todos os discípulos.

Consequentemente, atesta Moreira que, no evangelho de Lucas, os pobres não são espiritualizados, mas têm conotações concretas. São carentes economicamente, marginalizados e excluídos socialmente, ou seja, não possuem relevância na sociedade. Também nos Atos dos Apóstolos (At), o segundo volume da obra lucana, aprofunda mais essa radicalidade. O apóstolo Pedro, por exemplo, declara-se em absoluta pobreza, não tendo nem prata e nem ouro, mas somente a Palavra que revigora e reanima os cansados (cf. At 3,6; 4,32.34-35; 2,44-45; 4,37.). Portanto, no evangelho segundo Lucas, aparece nitidamente uma opção pelos pobres, contra a pobreza. A teologia lucana propõe uma mística evangélica que seja uma Boa Notícia para os pobres, e os ricos não são excluídos a priori, mas são convidados a abandonar a idolatria do capital e do poder e enxergar os pobres ${ }^{34}$.

"Os pobres recebem uma boa nova, são "evangelizados", à medida que são libertados de sua situação de miséria, de privação, de carência física ou social. Na categoria dos pobres ficam incluídos os cegos, surdos, coxos, leprosos. Este realismo corporal não só exclui toda espiritualização, mas ajuda a entender as ressonâncias humanas e sociais da situação em que se acham os pobres do evangelho. Doença e pobreza no mundo antigo constituem um binômio, já que os doentes e enfermos impossibilitados de produzir sua subsistência deviam muitas vezes se conduzir a mendicidade. Os doentes por sua vez ficavam a mercê de sua sorte desgraçada, no máximo, objeto de compaixão, se não eram por motivações religiosas ou sociais segregados ou menosprezados como seres inúteis e perigosos. Dos "pobres" fazem parte também os "pequenos", opostos aos doutos e sábios: são os indivíduos desprovidos de cultura, os analfabetos, que num ambiente religioso e controlado pelos peritos da lei sagrada, ficam excluidos dos privilégios e das distinções

33 MONASTERIO, R. A.; CARMONA, A. R. Evangelhos Sinóticos e Atos dos Apóstolos. São Paulo: Ave-Maria, 2000. p. 319.

34 MOREIRA, G. Os pobres na obra de Lc-At e em nós. Disponível em: <http://gilvander. org.br/site/os-pobres-na-obra-de-lucas-lc-e-at-e-em-nos/>. Acesso em: 20 fev. 2019. 
sociais. A estes, diz Jesus, é revelado o projeto salvifico de Deus (cf. Lc $10,21 ; 7,29-30)^{\prime \prime 35}$.

Nesse sentido, é oportuno fazer um pequeno esboço da situação destes grupos marginalizados, pois eles apresentam características singulares, mostram as chagas dos pobres daqueles tempos, inseridos na realidade lucana.

3.1 Pecadores: incluindo os públicos (cf. Lc 7,37; 19,7) saltam em primeiro plano na obra de Jesus, pois ele os busca (cf. Lc 19,7), se alimenta com eles (cf. Lc 5,29-31), perdoa-lhes (cf. Lc 7,48-50; 22,61s; 23,42s), desculpa-os (Lc 23,34), chama-os a seu seguimento (cf. Lc $5,27 \mathrm{~s}$ ). A justificativa desse privilégio é teológica, firmada exclusivamente na misericórdia de Deus Pai, que deseja ardentemente a volta de todos os seus filhos à casa e, por isso, enviou Jesus (cf. Lc 5,32; 19,9s). Assim, há grande alegria no céu quando um pecador se converte (cf. Lc 15). Então, Jesus faz acontecer a anistia radical de Deus (cf. Lc 4,19) que é recebida no reconhecimento do próprio pecado, acolhendo a misericórdia de Deus (cf. Lc 18,13s). ${ }^{36}$

3.2 Escravos: vale lembrar que, como em todo o mundo antigo, também em Israel existiam escravos e que, aqui, temos de entender essa situação dos escravos em toda a sua dureza. Ser escravo significa ser propriedade do outro. O escravo judeu tinha consciência de que se encontrava sob a proteção da lei e de que tinha de ser tratado como um assalariado que vende sua força de trabalho. Somente assim tinha chance de conquistar uma modesta propriedade. Sobretudo, ele depositava esperança em receber de volta a liberdade no ano sabático. Aqui se radica um traço totalmente humano da lei. Por outro lado, com os escravos pagãos a situação era outra, porque eles não tinham direito aos privilégios de que desfrutavam os escravos judeus. Por isso, não raro, estes eram aceitos na sinagoga como prosélitos ${ }^{37}$.

3.3 Mulheres: quanto às mulheres, Lucas sublinha que estavam entre as classes menos favorecidas e marginalizadas, mostrando importante destaque do papel da mulher desempenhado no Cristianismo, dando a elas um lugar especial, já que estas possuíam baixa posição social

35 FABRIS, R.; MAGGIONI, B. Os Evangelhos II. São Paulo: Loyola, 2010. p. 110-111.

36 MONASTERIO, R. A.; CARMONA, A. R. Evangelhos Sinóticos e Atos dos Apóstolos. São Paulo: Ave-Maria, 2000. p. 319.

37 GNILKA, J. Jesus de Nazaré: mensagem e história. Petrópolis: Vozes, 2000. p. 63-65. 
na Antiguidade. Coloca na sua obra mulheres como protagonistas e as menciona mais do que os demais autores do Novo Testamento. Além da mãe de Jesus, a Virgem Maria (cf. Lc 1,26-56;2,19,51), é o único autor gentio dos evangelhos a esbanjar adjetivos a Isabel (cf. Lc 1,39-45), a Ana (cf. Lc 2,36-38), à viúva de Naim (cf. Lc 7,11-17), à mulher pecadora (Cf. Lc 7,36-50) ,a Maria Madalena (cf. Lc 8,2), a Joana (cf. Lc 8,3),a Susana (cf. Lc 8,3), a Maria e Marta (cf. Lc 10,38-42), e à mulher com espírito de enfermidade (cf. Lc 13,10-17). Elas ainda estão nas parábolas de Jesus, seja na da moeda perdida (cf. Lc 15,8-10), ou na do juiz injusto (cf. Lc 18,1-8). Fica claro que Jesus quebra alguns paradigmas ou antigas tradições, tentando mudar a mentalidade e concepção arcaicas com relação à mulher e o seu caráter revolucionário. ${ }^{38}$

Evidencia-se aqui que Jesus inaugura uma experiência do Reino que valoriza a integridade e dignidade da pessoa, Ele acolhe e convive com os desprezados de seu tempo e isso confirma uma isenção com relação aos chamados sentimentos misóginos.

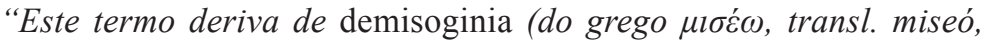
"ódio"; e yvvì, gyné, "mulher") que é o ódio, desprezo ou repulsa ao gênero feminino e às características a ele associadas (mulheres ou meninas). A misoginia é por vezes confundida com o machismo e com o androcentrismo, mas enquanto a misoginia se baseia no ódio ou desprezo, o machismo fundamenta-se numa crença na inferioridade da mulher e o androcentrismo desconsidera as experiências femininas perante o ponto de vista masculino" ${ }^{\prime 3}$.

Segundo Joachim Jeremias, Jesus é inovador diante do costume de afastar e isolar a mulher. De acordo com um antigo ditado sapiencial rabínico, não era aconselhável falar muito com uma mulher na rua e rezava outro, posterior, que isso era válido também com referência à própria esposa. A atitude de Jesus tem como consequência a ida das mulheres ao encontro d'Ele o que se percebe claramente na história da paixão, pois ali elas the demonstraram fidelidade maior do que a de seus discípulos ${ }^{40}$.

38 MONASTERIO, R. A.; CARMONA, A. R. Evangelhos Sinóticos e Atos dos Apóstolos. São Paulo: Ave-Maria, 2000. p. 321-322.

39 MARTINS, M. A. A relação de Jesus com as mulheres na perspectiva de Lucas. Disponível em: <http://tede2.pucgoias.edu.br:8080/bitstream/tede/887/1/MARQUES\%20 ALVES\%20MARTINS.pdf>. Acesso em: 19 abr. 2019. 
É verdade que, dessa forma, a prática de Jesus é também chocante para os padrões preestabelecidos dessa época, pois coloca significativos sinais libertadores para a vida das mulheres numa sociedade totalmente patriarcal. Nesse sentido, afirma Mackenzie que "a maneira com a qual Jesus tratava as mulheres é reveladora. Ele conhecia-lhes a vida e as fadigas cotidianas e se interessou por elas, o que se vê em muitas passagens bíblicas"41.

3.4 Samaritanos: este é um grupo de marginalizados que são privilegiados por Jesus, ainda que não tenham obtido tanto destaque como os outros grupos. Desprezam a Jesus e, por isso, a sua evangelização pertence ao caminho da Igreja (cf. Lc 9,52-56; At 8,4.25), porém aparecem como pessoas modelo de agradecimento (cf. Lc 17,11-19) e de misericórdia (cf. Lc 10,29-37). ${ }^{42}$

É interessante sobre esse assunto a pesquisa de Lohse ao destacar que, no tempo de Jesus, judeus e samaritanos não se relacionavam (cf. Jo 4,9), pois estes eram considerados estrangeiros pelos judeus (cf. Lc 17,18). A separação entre judeus e samaritanos provinha de longa data e aconteceu depois da conclusão do Pentateuco e antes da definição dos limites canônicos das outras partes do Antigo Testamento. Nesse tempo, pairava uma inimizade profunda entre judeus e samaritanos e a animosidade finalmente os levou à guerra. No ano 128 a. C., os judeus, sob o comendo de João Hircano, destruíram o templo do monte Garazim. Embora não tenha mais sido reconstruído, os samaritanos permaneceram fiéis ao seu lugar santo. Importante recordar, também, que a palavra "samaritano" era utilizada como insulto contra pessoas consideradas loucas (Jo 8,28). Por outro lado, Jesus não apresenta ação de um judeu, mas a de um samaritano, como exemplo de amor ao próximo, oferecido de maneira gratuita (Lc 10,30-37). Narra-se que um samaritano, e não um judeu, deu glória a Deus após a cura da lepra (Lc 17,11-19). Hesitante no início de Mt 10, 5ss, mostra que a comunidade primitiva rapidamente superou a separação existente entre judeus e samaritanos e levou o Evangelho para a Samaria (cf. At 8,4-25) ${ }^{43}$.

41 MACKENZIE, J. L. Dicionário bíblico. São Paulo: Paulus, 1983. p. 636.

42 MONASTERIO, R. A.; CARMONA, A. R. Evangelhos Sinóticos e Atos dos Apóstolos. São Paulo: Ave-Maria, 2000. p. 322.

43 LOHSE, E. Contexto e Ambiente do Novo Testamento. S. Paulo: Paulinas, 2000. p. 14-15. 
Por outro lado, também é valido recordar que os samaritanos eram considerados impuros, sobretudo pelos sulistas. O preconceito provinha do fato de eles se misturarem com outros povos, o que era proibido pela lei, e misturavam, também, a religião hebraica com outras religiões e, nesse sentido, eram também considerados hereges. Embora estes vivessem na religião herdada do Sinai, se negavam a aceitar Jerusalém como o centro da prática e da orientação religiosa e organizavam a vida religiosa de maneira autônoma prestando culto e fazendo suas festas litúrgicas no monte Garizim e não no templo ${ }^{44}$.

3.5 Mendigos: eram muitos os mendigos existentes, como afirmam os evangelhos, e entre os mendigos encontravam-se, sobretudo enfermos e incapacitados para o trabalho, como cegos, aleijados e cativos. Essa era uma realidade triste que o próprio sistema fazia crescer frente a tantas desigualdades e situações alarmantes de miséria. Confirma Gnilka que "percebia-se isso na estrada dos peregrinos em Jerusalém, pois ali havia lugares preferidos para mendigar, por exemplo, junto à porta do templo (cf. At 3,2)" ${ }^{45}$ E porque na porta do templo? São muitas as opiniões, mas parece plausível que a escolha deste local se deva à logística de que todos entravam no templo passando pelo átrio das mulheres, assim, o apelo dos necessitados se tornava um clamor pela solidariedade, um apelo à equidade.

\section{4 Ética econômica e discipulado}

É bem verdade que os bens podem nos conduzir por caminhos contrários ao projeto do Reino, mas é bem verdade também que é a falta de compaixão e de solidariedade que Jesus não suporta, sobretudo nos seus discípulos e, consequentemente, não suporta em nós.

É devido a isso que Lucas apresenta a vida da primitiva comunidade de Jerusalém num contexto em que os ideais de unidade e fraternidade, este último muito apreciado no mundo helenístico, são realizados mediante à generosa partilha de bens por parte dos crentes (cf. At 11,28-30). E enfatiza que estes exemplos de participação e ajuda aos pobres eram tanto mais necessários quanto às comunidades cristãs helenísticas, às quais

\footnotetext{
44 VV.AA. Introdução ao Segundo Testamento - Eu vim para que todos tenham vida em plenitude. S. Paulo: Paulus, 2014. p. 22.

45 GNILKA, J. Jesus de Nazaré: mensagem e história. Petrópolis: Vozes, 2000. p. 67.
} 
Lucas endereça a sua obra e podiam se dizer abastadas em comparação com os primeiros destinatários do evangelho na Palestina.

"Além disso, o ambiente pagão em que viviam menosprezava visceralmente a condição de pobreza, ao invés de remediá-la pela generosa ajuda fraterna. Dai se compreende a preocupação pastoral de Lucas em insistir sobre o problema dos bens e seu uso cristão" $" 46$.

Para Fabris, está aqui a novidade do evangelho que traz um novo valor dado à esmola ou distribuição de bens aos pobres, o grande chamado do amor para com o próximo. Nesse sentido, enfatiza que, na tradição bíblica, o termo eleemosynê traduz o vocábulo hebraico sedaqah, "justiça", e ainda acrescenta que a prática da chamada esmola-justiça faz parte da obrigação que todo israelita tem em socorrer os mais fracos da comunidade. Portanto, Jesus revela a nova exigência do amor para com o próximo e da solidariedade humana, ou seja, um amor que supera o horizonte do clã ou seita religiosa, das barreiras nacionais e culturais, sendo também uma solidariedade que não conhece limites ou restrições $(10,29-37)^{47}$.

Harrington lembra ainda da parábola do bom samaritano (cf. Lc 10,2937) e afirma que "Jesus achou que só através dessa história pungente e sugestiva, tirada do mundo cotidiano de seu povo, poderia inculcar-lhe a verdade de que todas as barreiras, todas as distinções de pessoas caem perante as exigências absolutas do amor" $"$.

Chega-se, assim, ao motivo da Palavra de Deus afirmar que o dinheiro é iniquidade (cf. Lc 16,9). Realmente, o dinheiro é iníquo porque cria abismos enormes entre as pessoas, gerando desamor. Consequentemente, a riqueza pode torná-las insensíveis e cegas, talvez até apáticas, como o rico da parábola de Lázaro e do homem rico de Lucas (cf. 16,19-31), alguém que não consegue enxergar o seu próximo. Só que com a morte dos dois, o rico feliz, tem sua justiça, pois vai para um lugar de tormentos e já, por sua vez, Lázaro, o pobre, está em situação acolhedora e feliz, pois acabou o seu exílio pobre, ele está bem. Confirma Ratzinger que "esta parábola, à medida que nos desperta, é, ao mesmo

46 FABRIS, R.; MAGGIONI, B. Os Evangelhos II. São Paulo: Loyola, 2010. p. 112.

47 FABRIS, R.; MAGGIONI, B. Os Evangelhos II. São Paulo: Loyola, 2010. p. 114.

48 HARRINGTON, W. J. Chave para a Bíblia: a revelação: a promessa: a realização. São Paulo: Paulus, 1985. p. 481. 
tempo, um apelo para o amor e para a responsabilidade que precisamos agora ter para com nossos irmãos pobres, quer no plano da sociedade mundial, quer na pequenez do nosso cotidiano"49

Deduz-se que o motivo de praticar o amor com o próximo é um apelo coerente, já que onde existe um marginalizado e, ao lado, uma acumulação de bens é necessária uma ajuda desinteressada e sem limites. Conclui-se que, no uso dos bens, o ideal não é nunca a privação, mas a caridade, que se esforça de todas as maneiras, a fim de que ninguém seja submetido pela necessidade. Somos chamados a estar no caminho de Jesus Cristo, o qual "sendo rico, fez-se pobre por vós, para que nos tornássemos ricos por meio da sua pobreza” (cf. 2Cor 8, 9). É preciso diminuir a iniquidade, mas como? Fazendo essa "tzedeka" ou mesmo "Zedacá" (צhebraico: צדקה) acontecer. É preciso lutar por justiça, fazer justiça, promovendo o bem a todos, ajudando o próximo, jamais rompendo com o amor-caridade.

\section{Conclusão}

Ao refletir sobre os pobres, Lucas entra no mundo da Palestina e consegue visualizar a crosta de marginalizados: crianças, mulheres, deficientes, mendigos, escravos, pecadores, samaritanos, doentes e, consequentemente, não poderia ser indiferente a esta situação. Por isso, ao constatar uma realidade de preconceitos e desigualdades, mostra que não somente entendeu a ética do amor, como também insistiu em ações transformadoras dentro das comunidades lucanas, apresentando a estas o desafio de testemunharem que miséria não combina com evangelho e que a luz do evangelho é capaz de impulsionar ações diferenciadas em socorro dos menos favorecidos.

Nesse sentido, compreende-se o porquê de sua atenção se voltar para as pessoas simples, pobres, que preservaram sua dignidade e estão dispostas a sacrifícios por amor a Deus e aos seres humanos, mostrando o rosto de Jesus em Lucas como o verdadeiro benfeitor. E o motivo de tal escolha fica evidente no próprio Jesus de Nazaré, que apresentou uma predileção por essas pessoas, pois Ele quer reintegrar a fé em Israel, nos excluídos do Templo ou da Comunidade.

49 RATZINGER, J. Jesus de Nazaré: primeira parte: do batismo no Jordão à transfiguração. S. Paulo: Planeta do Brasil, 2007. p. 190. 
Fica claro que Jesus mostra aos seus discípulos a incompatibilidade entre o Reino e o apego às riquezas, em uma insistência para não centralizarmos a própria vida nos bens passageiros deste mundo, mas para assumirmos a solidariedade e a partilha para com os irmãos mais necessitados. Portanto, cabe a nós o desafio de um olhar apurado ao próximo, pois saber olhar é saber amar. É necessário um olhar que enxergue os pobres e que perceba que a pobreza material é sempre negativa e também rejeitada por Deus, fruto do pecado ou das circunstâncias padecidas, sendo um fato social que desumaniza quem sofre e desonra a sociedade que o provoca e o tolera.

Também cabe, aqui, uma reflexão sobre a riqueza que, para Lucas, constitui um perigo grave que pode impedir alguém de tornar-se cristão. O homem pode transformá-la num ídolo, num deus, que lhe dá tudo o que deseja. Quanto mais riquezas alguém possui, maior será a probabilidade de sentir a tentação de amarrar o coração aos próprios tesouros, a ponto de se tornar um obstáculo grande para quem pretende entrar no Reino dos Céus. O desprendimento de tudo o que possui exige um ato de generosidade tão grande que só mesmo um milagre de Deus nos permite realizar.

É evidente que não se trata de desprezar os bens deste mundo, mas de usá-los de maneira correta, para valorizá-los, colocá-los no plano de Deus a serviço de quem se encontra necessitado.

Há um pedido evangélico de não pôr o coração nas coisas, ou seja, não se deixar dominar pelo poder de atração das realidades materiais. Existem coisas que são más em si: droga, vícios. Mas mesmo as coisas boas se tornam más quando não são bem usadas, quando se põe nelas a meta da vida. $\mathrm{O}$ apego pode afastar as pessoas, definitivamente, de Deus e é preciso ter o cuidado de não colocar a moeda em cima do nome Deus.

Por fim, que este artigo possa despertar o fim do apego, e que desperte a solidariedade, um chamado pela justiça dentro dos corações, provocando-nos mudanças, pois, se quisermos representar a figura de um cristão, teremos de desenhar um homem desprendido, com os braços e o coração abertos como Cristo na cruz, portanto, o cristianismo é o contrário da mesquinhez.

Quando não somos capazes de ser solidários com Deus e com o próximo, acabamos não sendo generosos conosco mesmos: quem dá 
pouco, recebe pouco, porque estreita seu coração, tornando-o incapaz de receber e reter o amor que recebe.

A solidariedade consiste em dar o que não é devido: o que não se deve por simples justiça e que, por isso, ninguém espera. Consiste em dar o que custa, heroicamente, e esse coeficiente do heroísmo é o que converte a caridade natural em entrega cristã.

\section{Referências}

AGUIRRE, Rafael; BERNABÉ, Carmen; GIL, Carlos. Guías de lectura de lós evangelios de Mateo, Marcos e Lucas. Estella (Navarra): Verbo Divino, 2014.

CASALEGNO, A. Lucas: a caminho com Jesus missionário. São Paulo: Edições Loyola, 2010.

DILlMANN, R.; PAZ, C. A. M. Comentario al Evangelio de Lucas: Um comentário para la actividad pastoral. Estella (Navarra): Verbo Divino, 2006.

FABRIS, R.; MAGGIONI, B. Os Evangelhos II. São Paulo: Loyola, 2010. FITZMYER, J.A. El Evangelio según Lucas: Introducción General. vol. I, Madrid: Cristiandad, 1986.

GNILKA, J. Jesus de Nazaré: mensagem e história. Petrópolis: Vozes, 2000. GONZALES, Justo. Faith and Wealth: A History of Early Christian Ideas on the Origin, Significance, and Use of Money. Harper \& Row, San Francisco, 1990.

HARRINGTON, W. J. Chave para a Bíblia: a revelação: a promessa: a realização. São Paulo: Paulus, 1985.

JEREMIAS, J. Teologia do Novo Testamento. São Paulo: Hagnos, 2008.

LIBÂNIO, J. B. Linguagens sobre Jesus 3: de Cristo carpinteiro a Cristo cósmico. São Paulo: Paulus, 2013.

LOHSE, E. Contexto e Ambiente do Novo Testamento. S. Paulo: Paulinas, 2000.

LOUW, J.; NIDA, E. Léxico grego-português do Novo Testamento: baseado em domínios semânticos. Barueri: Sociedade Bíblica do Brasil, 2014.

MACKENZIE, J. L. Dicionário bíblico. São Paulo: Paulus, 1983. 
MAZZAROLO, I.; KONINGS, J. Lucas o evangelho da graça e da misericórdia. S. Paulo: Loyola, 2016.

MONASTERIO, R. A.; CARMONA, A. R. Evangelhos Sinóticos e Atos dos Apóstolos. São Paulo: Ave-Maria, 2000.

MORGENTHALER, R. Statistik des Neutestamentlichen Wortschatzes. Zürich-Frankfurt am Main: Gotthelf-Verlag, 1958.

PEREIRA, I. Dicionário Grego-Português Português-Grego. 5. ed., Porto: Apostolado da Imprensa, 1976.

RATZINGER, J. Jesus de Nazaré: primeira parte: do batismo no Jordão à transfiguração. S. Paulo: Planeta do Brasil, 2007.

SEGUNDO, J. L. A história perdida e recuperada de Jesus de Nazaré. Dos sinóticos a Paulo. São Paulo: Paulus, 1997.

SCHNELLE, U. Teologia do Novo Testamento. Santo André: Academia Cristã; São Paulo: Paulus, 2010.

TEISSEN, G.; MERZ, A. O Jesus histórico: um manual. S. Paulo: Loyola, 2004.

VV. AA. Introdução ao Segundo Testamento - Eu vim para que todos tenham vida em plenitude. S. Paulo: Paulus, 2014.

\section{Meios eletrônicos}

MARTINS, M. A. A relação de Jesus com as mulheres na perspectiva de Lucas. Disponível em: <http://tede2.pucgoias.edu.br:8080/bitstream/ tede/887/1/MARQUES\%20ALVES\%20MARTINS.pdf $>$. Acesso em: 19 abr. 2019.

MOREIRA, G. Os pobres na obra de Lc-At e em nós. Disponível em: http://gilvander.org.br/site/os-pobres-na-obra-de-lucas-lc-e-at-e-em-nos/. Acesso em: 20 fev. 2019.

SANTOS, P. E. C., O 'ebyôn ("pobre") e o 'anî ("pobre") dentro do livro do Deuteronomio. Disponível em: $<\mathrm{http}$ ///revistas.fflch.usp.br/vertices/ article/view/469>. Acesso em: 06 fev. 2019. 